\title{
Homelessness in delhi: roots, rhetoric and realities
}

\begin{abstract}
Urban homeless are the most vulnerable section who epitomizes explicit social exclusion. There has been very little ink given to homelessness which is one of the complex social problems. The available studies mostly centered on surface issues of homelessness. This paper looks at the homelessness its meaning, causative factors, social work's intervention in developing policy perspectives for homelessness.
\end{abstract}

Volume I Issue I - 2017

\author{
Sanjoy Roy, Chandan Chaman \\ Department of social work, University of Delhi, India
}

Correspondence: Sanjoy Roy, Associate Professor, Department of Social Work, University of Delhi, India, Email sanjoyroy30@gmail.com

Received: November 18,2016 | Published: March 07, 2017

\section{Introduction}

Urban homeless are the most vulnerable section in our society who epitomizes explicit social exclusion. One can imagine the gravity as well as multidimensionality of the issue that there are various definitions of homeless which actually is creating more problem than containing it. There has been very little ink given to homelessness which is one of the complex social problems. Available research in the Indian context amply talks about the living conditions of homeless people and see it as lack of shelter when it comes to defining homeless, an administrative aspect becomes over-riding feature. For instance, Homeless people are understood as those who don't live in 'census houses' by the Census of India and any 'structure with a roof' is considered as 'census house. ${ }^{1}$ But largely the people who sleep rough are considered homeless and also people who spend days and nights in shelter houses are referred homeless. These homeless people consist of single women, old and children, people having special needs and there are others who are involved in substance abuse.

The homelessness debate often revolves around the lack of house. Hardly any study or exploration sees it as lack of home. The perspective on lack of home can give a real picture of deprivation. What has been happening actually is that homeless people has been provided mainly temporary shelters rather than dealing with the problem holistically. A shelter can hardly become a home. The activists are taking the cause at greater heights with homeless but the conceptualization of a home is missing in their scheme of things. The major aim of the study is to understand the causative factors ${ }^{2}$ of homelessness with the problems faced by homeless people. It deals with the root of the problem which often dies down in rhetoric. Holistic meaning of homelessness is captured. Then the study looks at the interventions for the homeless people and then suggestions for better interventions. Attempt is here to understand the rhetoric around the homelessness. It notes the state inability to tackle homelessness from the roots.

This study is based in Delhi, the National Capital territory which has vast homeless population. It is the result of in-depth interview of 30 professionally qualified and trained social workers working with homeless. Focus group discussions were also conducted with many groups of homeless. After brief introduction, the methodology adopted is explained and then the findings are presented.

\section{Understanding homelessness}

Homelessness is a much less understood term across the globe has pointed out that at different periods of time; different concepts have been used to ${ }^{3}$ understand homeless population have been dominant viewpoint which sees homelessness as individual problem or structural problem. Has engaged himself in an ambitious task to understand the homelessness by reviewing the available literature and it provides an important insight into the conceptualization of homelessness. The researcher of the present study also found himself in the same line of thinking when Somerville says that homelessness is just not only about paucity of shelter or lack of four walls but it consists of different deprivations of different dimensions. These are "physiological (lack of bodily comfort or warmth), emotional (lack of love or joy), territorial (lack of privacy), ontological (lack of rootedness in the world, anomie) and spiritual (lack of hope, lack of purpose)" (p. 384). If we take into all dimensions together, it reflects what the home should be which has been discussed by Heidegger, Berger and Zaricznyj. He further says that all these dimensions must be recognized because brick and mortar facility can hardly be remedy for homelessness. This argument gets reinforced when he mentions the cases of women who fled their homes because of abuses and here homelessness becomes solution than to be homed.

${ }^{4}$ has provided an interesting yet important typology of homeless which explained their causation as "slackers", "lackers", "unwilling victims". This categorization has influenced the intervention approaches. ${ }^{5}$ has coined another three types of homeless people which were "bad", "mad" and "sad". "Bad" represented deviants, "mad" represented vulnerable or ill and "sad" represented helpless victims. Says that this sort of viewpoint has become a new orthodox which hardly looks beyond the individual and structural factors. At the global level, three types of explanations have been dominating which is beautifully articulated by as "sin talk", "sick talk" and "system talk". "Sin talk" basically blames the homeless for their situation. In this sort of talk homeless are held responsible for their situation due to their alleged indulgence in drugs and drinking and this view has been reigned till since 1960s. After 1960s, "system talk" became more acceptable and prevailed till 1980s which basically hints at structural factors as reasons for homelessness. Structural factors include unemployment and lack of opportunities. Post 1980s "sick talk" has gained momentum where homeless people are seen as suffering from many disorders like mental and physical.

\section{Methodology}

One of the first objectives of the study was to explore the major 
causes of homelessness. The second objective was to understand the problems and challenges faced by homeless people. The third objective being the understanding of the interventions for homeless and the fourth objective was to develop a suggestive framework for better policies and programmers for the homeless people.

\section{Sample and procedure}

All the trained and professionally qualified social workers working with homeless in Delhi (National Capital Territory) constitute the universe of the study. It included the professional social workers both from government as well as non-government organizations as population for the study.

A purposive sampling method was used to draw sample from the population. This method was used because universe was not defined and identifying professionally trained and qualified social workers working with homeless was an uphill task. There are minuscule trained and qualified social workers, so purposive sampling became the obvious choice. Similar studies also had also used this sampling method. The respondents have been identified on the basis of correspondence and discussion with practitioners in the field and visiting organizations. The researcher selected social workers working in different districts to give more representation of the universe. Also, the respondents further divided on the basis of their work with homeless men, women and children. In this way, forty social workers were identified. The social workers having less than one year experience was precluded. With this criterion, the total respondents were thirty social workers. Also, as adequate enquiry was essential to understand their perspectives on the causes of homelessness and their practice, that is why this kind of sample size was pursued

\section{Data collection and analysis}

The study primarily used in-depth interview schedule to collect information from the social workers. In- depth interview schedule had open ended questions to obtain maximum information regarding the causes of homelessness and the interventions for combating it. As the primary data were collected through open-ended questions, emerging themes were recognized and analyzed. The secondary data were amalgamated with the primary in analysis.

\section{Findings}

\section{Homeless people in Delhi: profile}

There is stark absence of accurate numbers of homeless people in the capital city. The reasons are obvious that (i) this type of population continues to fluctuate; (ii) the enumerators had not done their job properly and (iii) the homeless people also tries to hide themselves from getting counted. According to the 2011 census, Delhi's 'houseless' population stood at 46,076 . Contrary to this, in the same year, the Indo-Global Social Service Society (IGSSS) found 2,46,800 after conducting an independent enumeration of the homeless population in Delhi. It is frightening to note that out of 46,076 houseless population, there are 3, 594 children are houseless as per the census 2011. One can imagine the real figures.

This contradictory figure is not confined only to the year of 2011. But also in 2001 census, the lacunae in enumeration were highlighted. On the one hand, the Census of India (2001) had provided the number of 24,996 homeless people in the city, ${ }^{1}$ on the other hand, ${ }^{6}$ an NGO who works with homeless, had found 52,765 homeless $^{7}$ people in Delhi. There are many other studies which have been reflecting different numbers.

Mission Convergence, which has been the Delhi government flagship programme, has conducted a survey in 2010 and found 55,955 homeless people which has given a clear picture of concentration of homeless in districts of Delhi. Let's look at the geographical distribution of homeless. ${ }^{8}$

As we know the homeless people are concentrated in few areas of the city. The data from the Table 1 shows that central Delhi has the highest number of homeless accounting for 25 per cent of the total identified population. Then, the north-west has 19.3 per cent of homeless people followed closely by north district at 14.2 per cent. The popular places which have seen huge concentration of this population are the places around Hanuman Mandir and Connaught place in central Delhi; Azadpur in north Delhi; Yamuna Pushta and the markets around it in east Delhi; Nizammudin and Kalkaji mandir in the south of the city.

Table I Geographical distribution of homeless

\begin{tabular}{lll}
\hline Districts & Total no. of homeless & Percentage \\
\hline North & 7967 & 14 \\
Central & 13988 & 25 \\
East & 4983 & 8.9 \\
West & 1781 & 3.2 \\
South & 9427 & 16.8 \\
New Delhi & 894 & 1.6 \\
North-east & 2747 & 4.9 \\
North-west & 10827 & 19.3 \\
South-west & 3341 & 6 \\
Total & 55955 & 100 \\
\hline
\end{tabular}

The small number of homeless women is not something to be satisfied with. But it indicates different forces at play. As per 2011 census, there are 37,836 males and woefully 9,240 females are found to be homeless. The reason for small numbers of females on the streets is because of their trafficking for commercial sexual exploitation.

\section{Homelessness - causative factors}

Before looking at the causative factors, a brief profile is presented. Let's now focus on the factors which make people homeless through the social workers views.

\section{Social workers perspectives on causation of homelessness}

One of the first open ended questions asked to respondents (social work practitioners), "What are the major causes of people becoming homeless"? The idea was to elicit as much responses as possible and to understand their conceptualization. Most of the social workers responded poverty as a major cause of homelessness with host of other causes (which are presented in Table 1)

In the context of Delhi, these are the major reasons which were pointed out by social workers are summarily put into a table (Table 2). 
Table 2 Social worker summary

\begin{tabular}{ll}
\hline I & Poverty \\
2 & Unemployment \\
3 & Mental IIIness \\
4 & Abandonment by family \\
5 & Migration \\
6 & Unaffordable accommodations \\
7 & Natural disasters \\
8 & Absence of family \\
9 & Abuses
\end{tabular}

If we look at the reasons mentioned in table, these all point to the structural problems or beyond individual controls. Barring one or two reasons, all indicate the bigger structural factors such as urban inequality, indifference, and prejudice. There seems no consensus on the root causes of homelessness. As indicated above, there are two major viewpoints which subsume the other factors. First is an individual factor and second is a structural factor but social workers recognize it as complex problem. The secondary data also informs that capitalism, insensitive state, changes in family structure etc. has amply made people homeless. More or less, it reflects the failings of the state. Let us talk some major issues which have been largely repeated by many social workers.

Table 3 Causes of homelessness

\begin{tabular}{lll}
\hline Causes & Total responses & $\begin{array}{l}\text { Percentage out of } \\
\mathbf{5 5 9 5 5} \text { responses }\end{array}$ \\
\hline Poverty & 38115 & 68 \\
Search of employment & $1367 \mathrm{I}$ & 24.4 \\
Family disputes & 988 & 1.8 \\
Natural calamities & 650 & 1.2 \\
IIIness & 458 & 0.8 \\
Displacement & $21 \mathrm{I}$ & 0.4 \\
Cheated & 206 & 0.4 \\
Crop failure & 86 & 0.2 \\
\hline
\end{tabular}

\section{Homelessness-a poverty problem not housing}

Respondents' data indicates that homelessness is a poverty problem rather than a housing problem. They noted that a popular perception is that it is a housing problem. It is worth mentioning that the scale of poverty is such that people do not need only shelter but food, clothes, medicines and many other basic items.

They have mentioned that it is open secrets that many times house allotted to people have been given for rent to earn some more money while they live in slum areas. This reflects that it is the poverty which compels people to give their houses to others. This fact gets substantiated when data from the 2010 survey of Mission Convergence looked at.

Few social workers have mentioned that the government is more tilted towards providing housing which is problematic as it overlooked the other potential characteristics of homelessness. Overall, there was wide consensus that core understanding of homelessness includes not only the simple fact of lack of house but lack of identity and lack of social ties resulting in exclusion. This consensus bridge the gap between the individual and structural factors as it not only included the individual but also the structure which creates the problem. Some have criticized the ambitious scheme of 'Housing for all' of the present government. It will serve no purpose.

One of the social workers who have 16 long years of experience working with homeless people who mainly consist of men and women, observes that:

People become homeless as they move from rural areas to the city for livelihoods and earn a pittance which forces them to be on streets. They have no awareness of the availability of shelter homes so that they can go there. This is one of the initial push which make them homeless and the story of vulnerability starts from there. It is the poverty, illiteracy, unemployment, lack of support from the government becomes responsible for the homelessness of the people.

\section{Problems faced by homeless people}

Multiple degrees of vulnerability characterize their daily lives in consonance with the earlier discussion that homelessness is a multidimensional problem. Each day is a monumental challenge for the homeless people. On the streets, they are the victims of police brutality and rich people annoyance. In shelters, there are issues of accessibility, abuse and rigidity. In the night, women become highly vulnerable as anyone can brush his hand over their bodies.

One of the major and degrading problems was the arrest and holding up of the homeless people under the provisions of Begging Act. The lack of identity cards and social support systems only compound the problem. The indifference of the people and the institutions only make their soul feeble.

\section{Living conditions}

For most of the homeless, land is the bed and sky is the blanket. It means that most of them live in the open. This has been the way of life for some for twenty years. They make their living by casual jobs like selling balloons, selling snacks. Few involve themselves in rag picking, rickshaw pulling and street vending. Often they are able to manage meals but sometimes they sleep without having meals. There are issues of keeping belongings, sanitation and bathing. Police brutalities are a common story shared by many. Sometimes, Police burn up their belongings in front of them as police believe their carrying garbage everywhere. Lucky are those who get to sleep in shelter homes. Many of the homeless are rag pickers and at the end of the day, they come to shelter with a bag of rags. That is why they are denied entry to shelter homes. Few work late into the night, so they prefer to sleep in the open. As shelter homes admit homeless by enquiring about their identity and background, few do not like to be questioned about their background. So, they avoid going to shelter homes. These are few of the reasons homeless people keep themselves away from the shelter homes. The random donations by rich people also entice homeless to be on streets. The loneliness in their life pushes many to experiment with drugs. Many a times, their hard earned money is easily stolen by fellow homeless people.

It is the winter which becomes the enemy of these people and it is the only time when the whole world talks about them. It means winter is highly damaging to them as chilling cold has taken many lives. 


\section{Abuses}

Many homeless children who are on streets are often runways from their families due to the physical abuse inflicted upon them. But the escapes from families do not keep them safe either. Once abused by family, they now get physically abused by police and local goons. Even in shelter homes children are vulnerable. One of the children was raped by a worker of the shelter which was widely reported in the media (August, 2015).

It is the women who are completely unsafe on the streets. Local goons brush their hand over the bodies of sleeping women on the streets in the darkness of the night. Even in shelter they are not secured. It was brought to researcher notice by many social workers that even girls living in children homes, recognized under JJ Act, are subject to sexual exploitation. In surveys on homeless people, there has been very less number of women found because they are trafficked and kidnapped for commercial sexual exploitation. Older persons are the worst sufferers after women. When they should be cared most, they are left to fend for themselves. I saw crying them and their pain overpowers them when they mention that their living children have abandoned them. This is a grave abuse where children are at loggerheads with their parents only.

\section{Health}

Due to harsh life and living conditions, many children and men turn towards drugs to appease themselves which in turn make them more vulnerable. Men, children and women all without family tries to escape the loneliness by intoxicating themselves. Men and women are generally found to be drunk in the night. It is very painful that this all is a personal choice of the homeless people just to escape from the pain and desolation of harsh street life.

One of the welfare officers mentioned that most of the homeless who are beggars who live with their wives end up in producing more and more children due to lack of awareness. It not only put the women health at risk but also of the children.

\section{Social worker's interventions with homeless people}

\section{Social workers in government setting}

The researcher had difficulties in locating trained and qualified social workers in government organizations but succeeded when one or two agreed for the interview. The researcher first met the District Child Protection officer of the North -west Delhi who had Post-graduate degree in Social Work. She mentioned that homeless children found on streets are rescued and put into children as well as shelter homes. When asked, 'what are the main goals in their work with homeless children'? She responded that 'safety', 'care' and 'protection' are the main goals in her work with homeless children. Then the second question followed which was regarding the intervention strategies to achieve those goals. There was some discomfort in distinguishing between the goals and interventions. But after clarifications, she responded that the moment a child is reported or spotted, a child protection plan is prepared and executed.

The next interview was with a welfare officer working in a government children home. She also mentioned the same goals of DCPO but added 'counseling' as a goal also. To achieve this goal, she plans counseling sessions as per the need. The other goals being care and protection are executed by preparing an 'individual care plan' and 'case work'.

Integrated Project for Homeless is a special programme of Mission Convergence, which is a flagship project of Government of NCT Delhi. Community health department of St. Stephens is designated as Mother NGO for this project. I interviewed four members of this project. Two were active rescue members. I am mentioning the account of two.

As obvious their goal was to 'rescue' homeless people and destitute in the night. They gave an interesting yet challenging account of their work.

We start our work by 8 in the night with our team. Our aim is to spot homeless sleeping on the streets. When we awake them, we often found them to be under the influence of alcohol. Then we counsel them to come along with us for recovery centres or to sleep in shelter homes. They often refuse and sometimes we spend four to five hours for one person in counseling and sometimes a whole night for one case. So it becomes very challenging

This account reflects the importance of 'counseling or talk skills' social workers need to have with the people. In other cases, through their counseling skills, they enquire about the acquaintances of the individuals if they have any and then they inform the family of the person if they have one. In this way, some individuals get integrated with their families.

\section{Social workers in non-government organization's settings}

Major interventions in this sector are done by Non-government organizations. There are 195 NGO's run shelter homes at present in Delhi (DUSIB). Major non- government organizations WHICH ARE working for homeless people are Society for Promotion of Youth and Masses (SPYM), Aashray Adhikar Manch (AAA), SamarthThe Professionals, Prayas, Aman Biradari, St. Stephens- MNGO, and Housing and Land Rights Network (HLRN). Though, all these organizations work with different objectives, the welfare of the homeless remains the common agenda. There is very little number of professionally qualified and trained social workers employed in these organizations but the workers from the other background possess the same conviction to serve the people.

Broadly, it can be said that the social workers working with homeless in this setting involve themselves in two main goals (i) service delivery and (ii) advocacy. Some of the practitioners mentioned that their organizations and the projects already have goals and they work to realize those goals. In terms of service delivery, they provide services related to as basic as food and cloth items to vocational training programmes. In terms of advocacy, a lot of mobilization and networking with government official is done. Advocacy is generally done to get the rights of the homeless people. It indicates that social workers are engaging with homeless both at micro, meso and macro levels from social work perspectives. Let's look at each briefly.

\section{Micro level interventions}

Social workers employed in the organizations rescues homeless people mostly in winter nights. Homeless people are counselled by them to go for shelter homes which has been cited as one of the challenging aspect. Most of the social workers also involve themselves in capacity building of homeless people. 
One senior social work practitioner reflected that micro-level intreventions seems easy but in reality very challenging. He says:

Individualistic interventions are not easy as they seem. After approching a homeless, talking to them is not easy. One needs to create a rapport first with being friendly and enthusing care. Undersatnding their thinking and staring where the beneficiary is of great importance. All this helps in concvincing the homeless to be in shelter than streets.

\section{Meso level interventions}

Social workers always tries to find out the acquaintances and family of the homeless people. Once, they found the presence of family of a homeless, they try to integrate them with their families. The basic idea is to prevent homelessness.

Most of the social work practitioners agree that homelessness can be prevented. In delhi, many under the influence of drugs or quarell in family leads to separation of the individual which cab be tackled by contacting families. One of the female social work practitioner shares that

"sometimes families welcome their lost ones and sometimes loathe them. Then, they provide some support in the form of vocational training to the people to sustain themselves who are very poor"

Meso level interventions reflect the preventive approch towrads practice which is one of the theoretical aspect of the social work.

\section{Macro level interventions}

Persuading homeless people to choose shelter homes than street has been one of the toughest task of the social workers. So apart from counseling, they organise street plays, campaigns to highlight the importance of staying in shelter homes. They advoctae for their rights by orgainising meets with RWAs to sensitize them about the stereotypical picture of homeless. Research and documentation is also done to influnce policy decisions.

Ashray Adhikar Abhiyan (AAA) has one of the leading organistions in the area of homeless. The programme officer here is a qualified and trained social worker. He mentioned that AAA is a movement whose main goals are empowerment and recognition of homeless people so that they can assert their rights.

In summary, it can be mentioned that most of the social workers offered multiple goals which reflects the complexity and multidimensioanlity of the problem. Also, the intreventions reflect two major theoretical approch. Fisrt is task-centred approach and the second preventive approach. But more often social workers uses an eclectic approach i. e. blending of few approaches.

\section{Suggestive views of social workers}

Though, they are recognizing that homelessness is a wider problem but it is not as explicit as it should be. It is good to learn that poverty is one of the biggest factors which create homelessness among people, but to recognize the forces behind the poverty and the bigger structural issues would be a desirable step for a better intervention. These are some major points which need to be taken into account for better policies and programmes.

\section{Home needs to be understood to understand homelessness}

One of the important gaps which social workers agreed is the focus on understanding the extent of deprivations of homelessness; that we need to explore the meaning of home. Simply equating homelessness with materialist things is only a myopic solution or intervention. Hence, there is a need to recognize and emphasize the power of home and avoid getting trapped in housing schemes. Once again, a more awareness of macro issues will lead to better interventions.

\section{Identity can jeopardize also}

Though, talking and thinking about identity crisis and intervening is a good start. In Delhi, identity should actually help in getting things done and drawing what one is entitled to. It should not make one a potential offender and easily targetable in times because of his identity only (discriminatory practices against minorities and marginalized). Anonymity is what an urban fellow like often and it is also a characteristic of cities and so the homeless. Identity must be protective first. In a city like us where our leaders are often known by their addresses, it is for the weak the address often becomes a liability.

\section{No empower without thinking power}

Social Workers are in love with 'empowerment' word. Nine times out of ten, we come across documents of organizations (both government and non-government) which as empowerment as main goal. Social Workers understanding and experience with these organizations informs that by giving something to deprived people, you empower them. But this actually gives power to the institutions and bureaucrats which provide those things. Power must be conceived in the form of individuals. Without the concept of power (read Foucault) empower becomes more mundane. While writing of these gaps and asserting a need to focus on macro issues may look like a utopian thinking and hardly put to practice, I am aware of its limitations. But isn't ideas important, more importantly for practice?

Another problem regarding intervention is that a good number of people who work with homeless are from different academic backgrounds. It is important to note here that homeless population is very heterogeneous in nature and always in fluctuation and mostly hidden. This creates a problem in homogenous interventions.

\section{Conclusion}

Coming to homelessness, the researcher has mentioned at length, that homelessness as a term is used in a very narrow form. Its complexity and wider meanings has not found many takers in the field. Homelessness is different deprivations in different forms. The metaphor of home should be used to have bigger interventions. In Delhi, roofless people are seen as homeless. In reality the meaning of 'rooflessness' is 'rootlesness'. One of the major causes of the homelessness as per respondents view is poverty and homelessness is seen as poverty problem not as housing. Unemployment is the second big cause which pushes people into homelessness. The social workers are working from a Human Rights perspective though more interventions were found to be around individual reformist. A psychosocial approach is what makes social workers see houseless people as homeless. The major goals of interventions are safety planning, rescue work, advocacy, street mobilization and service deliveries. Advocacy is one of the larger roles of social workers but there is a problem in its approach. Advocacy means two things speaking directly on behalf of the client and other helping the client on their own behalf. The former is in wide practice while the latter still needs to be realized.

\section{Acknowledgements}

None. 


\section{Conflict of interest}

The author declare no conflict of interest.

\section{References}

1. Mander, Harsh, Jacob Smita. Homeless death on the streets. New Delhi, India; 2010.

2. Peter S. Understanding Homelessness, Housing. Theory and Society 2013;30(4):384-415.

3. Busch-Geertsema, Fitzpatric. Effective homelessness prevention explaining reductions in homelessness in Busch-Geertsema Germany and England. European Journal of Homelessnes; 2008. p. 69-95.

4. Rosenthal. Imaging homelessness and homeless people: visions and strategies within the movement(s). Journal of Homelessness and Social Distress. 2000;9(2):111-126.
5. Resettling Seal homeless people. Russell House, Lyme Regis, England; 2005.

6. Ashray Adhikar Abhiyan. The capital's homeless: a preliminary study. New Delhi, India; 2001.

7. Sartre J. Being and Nothingness: a phenomenological essay on ontology. In: Barnes H. editor. New York: Washington Square Press; 1993.

8. Gowan T. Hobos, Hustlers and Backsliders: Homeless in san rancisco. University of Minnesota Press, Minnesota, USA: Springer; 2010.

9. Heidegger, Martin. Being and Time. In: by Joan Stanhaugh. Editor. State University of New York Press, Albany; USA, 1996.

10. Zaricznyj, Andrew, Timothy. Righting home. A critical hermeneutic study of home. Homelessness and the spaces in between (Doctoral thesis); 2004. 